\title{
Biocatalytic Transformation of 5-Hydroxymethylfurfural into 2,5-di(hydroxymethyl)furan by a Newly Isolated Fusarium striatum Strain
}

\author{
Alberto Millán ${ }^{1}$, Núria Sala ${ }^{2}$, Mercè Torres ${ }^{2}$ and Ramon Canela-Garayoa ${ }^{1, *}$ \\ 1 Chemistry Department, University of Lleida, Alcalde Rovira Roure 191, 25198 Lleida, Spain; \\ alberto.millan@udl.cat \\ 2 Food Technology Department, University of Lleida, Alcalde Rovira Roure 191, 25198 Lleida, Spain; \\ nsala@tecal.udl.cat (N.S.); merce.torres@udl.cat (M.T.) \\ * Correspondence: ramon.canela@udl.cat
}

Citation: Millán, A.; Sala, N.; Torres, M.; Canela-Garayoa, R. Biocatalytic

Transformation of

5-hydroxymethylfurfural into 2,5-di(hydroxymethyl)furan by a Newly Isolated Fusarium striatum Strain. Catalysts 2021, 11, 216. https://doi.org/10.3390/catal11020216

Academic Editors: Anwar Sunna and Richard Daniellou

Received: 19 January 2021

Accepted: 3 February 2021

Published: 6 February 202

Publisher's Note: MDPI stays neutral with regard to jurisdictional claims in published maps and institutional affiliations.

Copyright: (c) 2021 by the authors. Licensee MDPI, Basel, Switzerland. This article is an open access article distributed under the terms and conditions of the Creative Commons Attribution (CC BY) license (https:// creativecommons.org/licenses/by/ $4.0 /)$.

\begin{abstract}
The compound 2,5-di(hydroxymethyl)furan (DHMF) is a high-value chemical block that can be synthesized from 5-hydroxymethylfurfural (HMF), a platform chemical that results from the dehydration of biomass-derived carbohydrates. In this work, the HMF biotransformation capability of different Fusarium species was evaluated, and F. striatum was selected to produce DHMF. The effects of the inoculum size, glucose concentration and $\mathrm{pH}$ of the media over DHMF production were evaluated by a $2^{3}$ factorial design. A substrate feeding approach was found suitable to overcome the toxicity effect of HMF towards the cells when added at high concentrations $(>75 \mathrm{mM})$. The process was successfully scaled-up at bioreactor scale (1.3 L working volume) with excellent DHMF production yields (95\%) and selectivity (98\%). DHMF was purified from the reaction media with high recovery and purity by organic solvent extraction with ethyl acetate.
\end{abstract}

Keywords: 5-hydroxymethylfurfural; biocatalysis; 2,5-di(hydroxymethyl)furan; Fusarium; whole cells; biotransformation; platform chemical; biomass; bioreactor

\section{Introduction}

The preparation of compounds that rely on fossil resources, alongside the increasing demand for energy, represent a substantial contribution to climate change that could be averted by finding renewable alternatives. One such alternative is the conversion of biomass, which is available all around the world as high amounts of waste, into platform chemicals that can later be transformed into their corresponding high-value derivatives, in a process of adding value to residues [1,2].

The chemical 5-hydroxymethylfurfural (HMF) results from the dehydration of biomassderived carbohydrates. It can be transformed into a wide range of high-value derivatives of interest in different industries (2,5-dimethylfuran, 2,5-di(hydroxymethyl)furan, 2,5diformylfuran, 5-hydroxymethyl-2-furancarboxylic acid, 5-formyl-2-furancarboxylic acid and 2,5-furandicarboxilic acid) due to the presence of both one aldehyde group and one hydroxyl group that can undergo oxidation/reduction reactions. This makes it an interesting intermediate between biomass resources and chemical blocks [3,4]. HMF is also a by-product in the production of bioethanol from lignocellulosic biomass. It can be present in the fermenting broth at concentrations up to $46 \mathrm{mM}$, depending on the raw material and the treatment applied [5], and it has been identified as an inhibitory compound for sugar-fermenting strains [6,7]. Biodetoxification has been studied as a solution. In this process, HMF is transformed into its less toxic derivative 2,5-di(hydroxymethyl)furan (DHMF) [8-10].

DHMF is a high-value chemical used as an intermediate in the synthesis of resins, fibers, foams, drugs and crown ethers [11]. It has great potential as a substitute for petroleum based aromatic diols during polymerization reactions for the manufacturing 
of polyurethanes and polyesters thanks to the presence of two double bonds and two hydroxymethyl groups $[12,13]$. To date, DHMF is synthesized mainly by chemical methods starting from HMF. Although the yields obtained with the catalytic processes are high, they show drawbacks such as the use of high-cost chemicals and extreme conditions [11]. The biocatalytic preparation of DHMF remains an attractive alternative to the current chemical pathways due to its higher selectivity, mild conditions and environmental friendliness [14]. However, the toxicity of HMF towards microorganisms poses a hard challenge for its biotransformation into DHMF with whole cells, and literature is still limited in spite of all the significant advances performed in the last years using yeast and bacteria as biocatalysts [15-20]. This becomes apparent in literature regarding this biotransformation when performed with filamentous fungi, as it is scarce and focused on the biodetoxification of lignocellulosic material in the bioethanol production process. Amorphoteca resinae ZN1 and Pleurotus ostreatus have been proposed as a solution, tolerating concentrations of HMF $\leq 30 \mathrm{mM}$ [8-10]. Nevertheless, low or undescribed selectivity, poor HMF tolerance at high substrate concentrations and long reaction times make them not suitable for DHMF production.

Filamentous fungi have great potential for biodegradation, bioremediation and biotransformation purposes. Among them, Fusarium species are well-known for their capacity for extracellular protein production and their ability to break down and degrade complex compounds such as chemical pollutants and lignocellulosic biomass, and for this reason they are emerging as promising biocatalysts for industrial applications [21-23]. Different polysaccharides with antioxidant and immunomodulatory activities have been prepared from Fusarium [24]. Their recovery after the biotransformation processes would assist in the transition to a circular economy. Finally, products derived from the biotransformation with Fusarium can be labeled as "natural" [23].

In this work, we report for the first time the HMF biotransformation capability of different Fusarium species. A new F. striatum strain isolated by our group was selected to produce DHMF, and the HMF-tolerance level was studied. The effects of the inoculum size, glucose concentration and $\mathrm{pH}$ over the DHMF production were evaluated by a $2^{3}$-factorial design. A substrate-feeding approach was studied in order to increase the final product concentration in the media. Besides, a scale-up of the process in a bioreactor $(1.3 \mathrm{~L})$ and subsequent recovery of the product from the reaction media were performed.

\section{Results}

\subsection{Fusarium Screening}

All Fusarium species studied were able to transform $50 \mathrm{mM}$ of HMF to some extent. F. striatum metabolized $100 \%$ of the HMF within 24 h, while F. sporotrichioides, F. poae and F. tricinctum metabolized $95 \%$ of the HMF added within the same time (Figure 1a). Moreover, F. striatum, F. sporotrichioides, F. poae, F. chlamydosporium and F. tricinctum yielded DHMF with high selectivities ( $>95 \%$ ) (Figure 1b). The by-product 5-methylfurfural was identified and quantified in the biotransformation media in small concentrations and was considered for the calculation of the selectivity towards DHMF production. The products resulting from the biotransformation with F. sambucinum and F. culmorum are currently being studied.

F. striatum was selected to produce DHMF due to its high yield and selectivity towards DHMF production. Moreover, the culture of F. striatum under the conditions studied resulted in a broth without the formation of large filamentous mycelia and a yeast-like growth was observed (Figure S1 Supplementary material). It was preferred against the excessive growth of mycelia of the other species for its advantages regarding manipulation and process control [25]. 


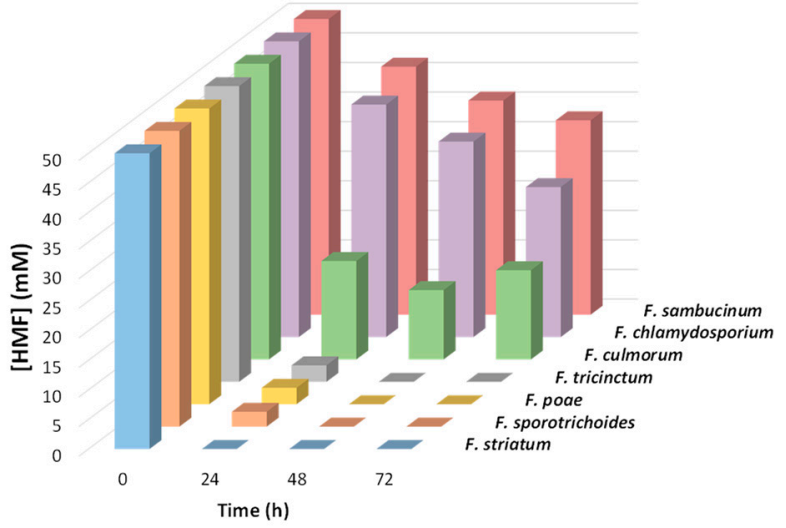

(a)

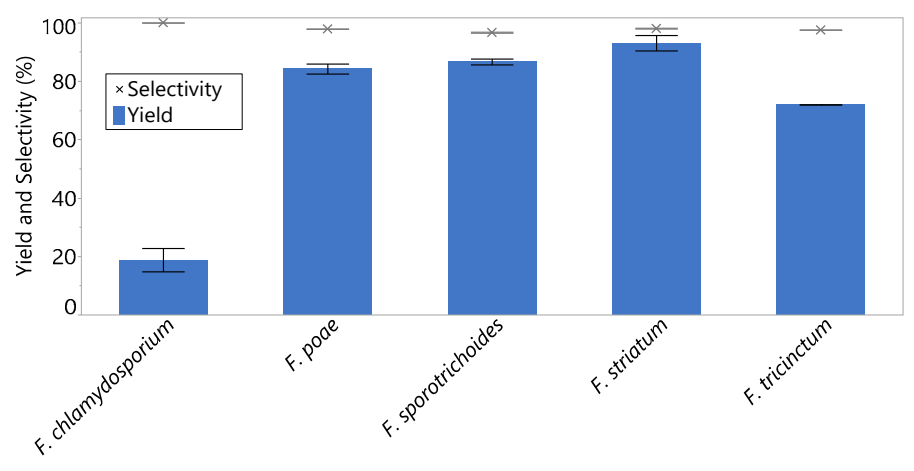

(b)

Figure 1. Biocatalytic synthesis of DHMF by different Fusarium species. Conditions: $50 \mathrm{mM}$ HMF, $15 \mathrm{~mL}$ ME medium, three discs biocatalyst, pH 7, $160 \mathrm{rpm}, 28^{\circ} \mathrm{C}$; (a) Concentration of HMF; (b) Yield and selectivity towards DHMF production.

\subsection{Effect of the Concentration of HMF}

The concentration of HMF is one of the critical points in the biocatalytic production of DHMF with whole cells due to the HMF toxicity towards microorganisms. Therefore, when working with whole cells, efficient biotransformation of HMF into DHMF is usually limited by the HMF-tolerance level of the microorganisms employed. Consequently, the tolerance of $F$. striatum was studied by increasing the concentration of HMF added (Figure 2). Yields towards DHMF production were quantitative ( $>95 \%)$ for concentrations of HMF equal or lower than $75 \mathrm{mM}$ under the conditions studied. However, lower yields were observed when the initial concentration of HMF was higher than $75 \mathrm{mM}$. The initial reaction rates $\left(\mathrm{V}_{0}\right)$ decreased when the initial concentration of substrate was increased. Therefore, there was an inhibitory effect of HMF, confirming its toxic effect towards the cells when added at high concentrations.

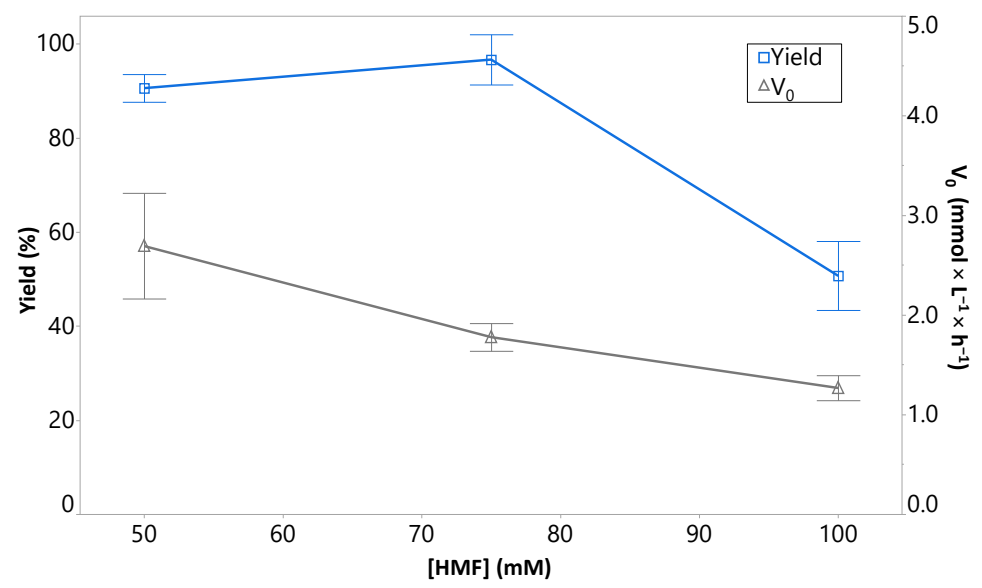

Figure 2. Effect of HMF concentrations on DHMF yields and initial reaction rates. Conditions: increasing concentrations of HMF: 50, 75 and $100 \mathrm{mM}, 15 \mathrm{~mL}$ ME medium, three discs biocatalyst, $\mathrm{pH} 7,160 \mathrm{rpm}, 28^{\circ} \mathrm{C}$.

\subsection{Effect of the Inoculum Size, Glucose Concentration and $p H$}

The Design of Experiments (DOE) offers many advantages compared to One-Factorat-a-Time (OFAT) approach in biotransformation optimization. For instance, it allows the estimation of the interactions of different variables, if any, as well as yielding more information from fewer experiments [26]. The effects of some conditions that may influence the DHMF production capability of $F$. striatum were evaluated by a $2^{3}$ factorial design. The 
inoculum size, concentration of the carbon source and $\mathrm{pH}$ were selected among the factors influencing the biotransformation process. The increase of the glucose concentration and inoculum size can have positive effects over the growth rate of the cells and the reaction rates of the HMF reduction, respectively [8,17]. Filamentous fungi are typically grown at $\mathrm{pH} 5$ tolerating a $\mathrm{pH}$ range from 4 to 9 . However, maximum growth of most of them is observed near neutral $\mathrm{pH}$ [27]. Therefore, the values selected were $20 \mathrm{or} 40 \mathrm{~g} / \mathrm{L}$ of glucose, three or six discs of inoculum size and $\mathrm{pH}$ values of 5 or 7 . The sequential addition of substrate, known as substrate-feeding, is an approach that can overcome the toxicity effects of substrates like HMF when added at high concentrations. Consequently, the effect of these factors was studied within one $(t=24 \mathrm{~h})$ and three $(t=72 \mathrm{~h})$ consecutive additions of substrate. Reduced models were performed by the removal of selected nonsignificant terms to produce more effective models. Table 1 shows the data corresponding to the $2^{3}$ full factorial design.

Table 1. $2^{3}$ full factorial design. All runs were performed by duplicate and the responses are expressed as means \pm standard deviations.

\begin{tabular}{ccccccccc}
\hline & \multicolumn{3}{c}{ Coded Levels } & \multicolumn{3}{c}{ Real Values } & \multicolumn{2}{c}{ Responses } \\
\cline { 2 - 10 } & $\mathbf{X}_{\mathbf{1}}$ & $\mathbf{X}_{\mathbf{2}}$ & $\mathbf{X}_{\mathbf{3}}$ & $\begin{array}{c}\text { Inoculum } \\
\text { Size (Discs) }\end{array}$ & $\mathbf{p H}$ & $\begin{array}{c}\text { [Glucose] } \\
\mathbf{( g} \times \mathbf{L}^{-\mathbf{1})}\end{array}$ & $\begin{array}{c}\text { mmol DHMF } \\
\mathbf{( 2 4} \mathbf{h})\end{array}$ & $\begin{array}{c}\text { mmol DHMF } \\
\mathbf{( 7 2} \mathbf{~ h})\end{array}$ \\
\hline 1 & -1 & -1 & -1 & 3 & 5 & 20 & $0.81 \pm 0.08$ & $1.41 \pm 0.13$ \\
2 & 1 & -1 & -1 & 6 & 5 & 20 & $0.96 \pm 0.07$ & $1.31 \pm 0.21$ \\
3 & -1 & 1 & -1 & 3 & 7 & 20 & $0.85 \pm 0.04$ & $2.12 \pm 0.31$ \\
4 & 1 & 1 & -1 & 6 & 7 & 20 & $1.02 \pm 0.03$ & 2.141 \\
5 & -1 & -1 & 1 & 3 & 5 & 40 & $0.78 \pm 0.07$ & $1.18 \pm 0.26$ \\
6 & 1 & -1 & 1 & 6 & 5 & 40 & $0.95 \pm 0.02$ & $1.31 \pm 0.00$ \\
7 & -1 & 1 & 1 & 3 & 7 & 40 & $0.80 \pm 0.09$ & $1.58 \pm 0.32$ \\
8 & 1 & 1 & 1 & 6 & 7 & 40 & $0.95 \pm 0.06$ & $1.90 \pm 0.37$ \\
\hline
\end{tabular}

In the analysis performed within $24 \mathrm{~h}$ of the first addition of HMF only the inoculum size showed a significant effect on DHMF production $(p<0.05)$. With the addition of six discs of biocatalyst, $0.97 \pm 0.04 \mathrm{mmol}$ of DHMF were produced; while with the addition of 3 discs of biocatalyst $0.81 \pm 0.04 \mathrm{mmol}$ of DHMF were produced. The glucose consumed within this time was significantly higher when the inoculum size consisted of six discs instead of 3. Glucose can act as a co-substrate and provide the reduced form of the cofactors needed for the reduction process $(\mathrm{NAD}(\mathrm{P}) \mathrm{H})[16]$. Moreover, glucose can increase the growth rate of the cells [8], which may explain why results were better as the inoculum size increased. The effect of the initial concentration of glucose of the media was not significant, probably because it was not completely metabolized even when it was added at the lowest concentration $\left(20 \mathrm{~g} \times \mathrm{L}^{-1}\right)$, and therefore there is no need to increase its concentration. The effect of $\mathrm{pH}$ and the interactions among parameters were not significant either.

Interestingly, in the analysis performed within three additions of substrate $(72 \mathrm{~h})$ only $\mathrm{pH}$ showed a significant effect on the DHMF production $(p<0.05)$. When the $\mathrm{pH}$ of the media was initially adjusted at 7, $2.04 \pm 0.24 \mathrm{mmol}$ of DHMF were produced; while when the $\mathrm{pH}$ was initially adjusted at $5,1.42 \pm 0.22 \mathrm{mmol}$ of DHMF were produced. $\mathrm{pH}$ of the media experienced a continuous decrease attributable to the production of organic acids, although this is not the only possible reason [28]. Therefore, having an initial $\mathrm{pH}$ of 7 can delay the acidification of the media and provide a more suitable environment for the reduction reaction after long reaction times and three consecutive additions of substrate. The effect of the initial concentration of glucose was not significant, as it was not completely consumed when $20 \mathrm{~g} \times \mathrm{L}^{-1}$ were added (there were $4 \mathrm{~g} \times \mathrm{L}^{-1}$ remaining). Therefore, $20 \mathrm{~g} \times \mathrm{L}^{-1}$ of glucose are enough under these conditions and the process is less expensive if glucose is added at lower concentrations. Moreover, there were no significant differences in the glucose consumed between both levels of inoculum size at this time, which can 
explain the lack of significance of this factor after three additions of substrate. To evaluate whether glucose is needed for the process, an assay was performed in a glucose-free malt extract media under the optimized conditions. Yields of $22.85 \pm 2.54 \%$ were obtained within $24 \mathrm{~h}$, indicating that the presence of glucose is essential for the biotransformation under these conditions.

Based on the statistical analyses, $20 \mathrm{~g} \times \mathrm{L}^{-1}$ of glucose and $\mathrm{pH} 7$ were selected as the optimal conditions, and the inoculum size and type were further optimized.

\subsection{Inoculation with Spores}

The inoculation of $F$. striatum from a suspension of spores was evaluated in order to optimize the inoculum size and type in the DHMF production. The addition of a known concentration of spores allows higher reproducibility of the results and greater control over the amount of biocatalyst added when compared with the addition of fungal discs. Moreover, fungal morphology in the submerged culture and the course of the biotransformation are highly influenced by the type of the inoculum [27].

Nutrient limitation and light presence are two of the most common mechanisms used to induce sporulation in filamentous fungi. Therefore, the effect of these two variables was assayed with a two-way ANOVA. There was a significant effect of the visible light, media and interaction of both variables, indicating complex mechanisms undergoing in the sporulation of F. striatum (Figure 3). The highest concentration of spores was obtained in the ME media in the presence of visible light, which means that nutrient depletion does not induce the sporulation of F. striatum under the conditions assayed. This should not be surprising, as the mechanisms by which fungal sporulation is induced by nutrient limitation and light remain unknown and depend on the microorganism studied [29].

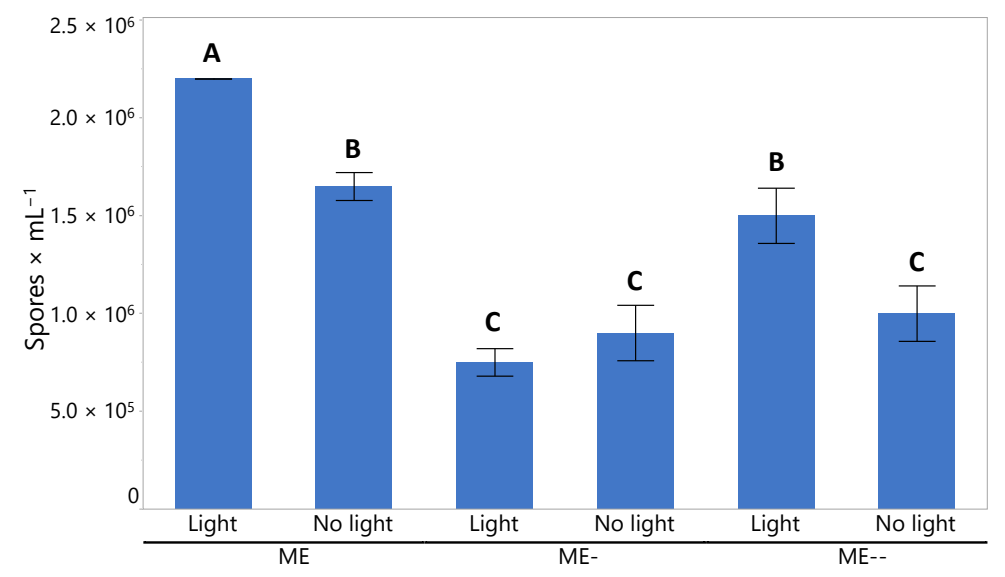

Figure 3. Effect of nutrient depletion and visible light presence on sporulation of F. striatum. Conditions: $28^{\circ} \mathrm{C}$, 10 days, presence or absence of light. Media: $\mathrm{ME}\left(20 \mathrm{~g} \times \mathrm{L}^{-1}\right.$ glucose, $20 \mathrm{~g} \times \mathrm{L}^{-1}$ malt extract, $1 \mathrm{~g} \times \mathrm{L}^{-1}$ peptones from soybean, $15 \mathrm{~g} \times \mathrm{L}^{-1}$ agar $)$, ME- $\left(20 \mathrm{~g} \times \mathrm{L}^{-1}\right.$ glucose, $20 \mathrm{~g} \times \mathrm{L}^{-1}$ malt extract, $15 \mathrm{~g} \times \mathrm{L}^{-1}$ agar $)$, ME- - $\left(20 \mathrm{~g} \times \mathrm{L}^{-1}\right.$ glucose, $10 \mathrm{~g} \times \mathrm{L}^{-1}$ malt extract, $15 \mathrm{~g} \times \mathrm{L}^{-1}$ agar $)$. Light: presence of visible light. No light: absence of visible light. Means with different letters are significantly different (Tukey HSD test, $p<0.05$ ).

The inoculation with spores did not have any effect on the growth of $F$. striatum in the submerged culture, and therefore a homogeneous culture without the formation of large filamentous mycelia was observed as in the previous experiments performed by the addition of fungal discs. The addition of $1 \mathrm{~mL}$ of a suspension of $4.0 \times 10^{6}$ spores $\times \mathrm{mL}^{-1}$ led to higher yields $(92.8 \pm 5.6 \%)$ than the ones obtained with the addition of six discs within $24 \mathrm{~h}(71.8 \pm 2.3 \%)$. On average, $7.5 \times 10^{5}$ spores were obtained from each disc. This indicates that the better results obtained were most likely due to the change of the type of the inoculum, which may influence the metabolite and enzyme production of the cells [27]. Therefore, the inoculation with spores was selected for further 
experiments. Results could not be improved by further increases of the concentration of spores, probably due to nutrient limitation. Results may be improved by adding a higher inoculum size, but that would probably require higher concentration of nutrients in the media. Glucose was not completely consumed once HMF was metabolized, and therefore nitrogen may be the limiting nutrient. Peptones are added at a low concentration in the process $\left(1 \mathrm{~g} \times \mathrm{L}^{-1}\right)$ because they are some of the most expensive components in culture media [30]; therefore, the increase of peptone concentration was not considered in this study. Another alternative is the use of one media for the growth of the biocatalyst and another media for the biotransformation of HMF, allowing more freedom and control over the inoculum size [31]. For this purpose, a hydrolysate naturally containing both glucose and HMF could be used as media for the biotransformation, thus adding value to the waste [14]. HMF is present in pretreated lignocellulosic hydrolysates at concentrations up to $46 \mathrm{mM}$, while the glucose concentration in these hydrolysates can be up to $70 \mathrm{~g} \times \mathrm{L}^{-1}$ [5]. To evaluate the performance of $F$. striatum under high concentrations of glucose, the biotransformation was performed by adding an initial concentration of HMF of $75 \mathrm{mM}$ and initial concentrations of glucose up to $80 \mathrm{~g} \times \mathrm{L}^{-1}$ to the media. There were no significant differences on the yields or reaction rates in the range of glucose concentration from 20 to $80 \mathrm{~g} \times \mathrm{L}^{-1}$, indicating that $F$. striatum may be a perfect candidate to perform the biotransformation of HMF into DHMF using lignocellulosic hydrolysates as reaction media. Moreover, the biotransformation of high concentrations of HMF present in lignocellulosic hydrolysates by F. striatum may be of interest in the lignocellulosic ethanol industry, as DHMF showed to be less toxic and does not inhibit the ethanol fermentation (work in progress) [8-10].

\subsection{Substrate Feeding Approach}

A substrate-feeding approach was performed in order to overcome the toxicity effect of HMF when added at concentrations higher than $75 \mathrm{mM}$, and therefore to increase the final concentration of DHMF in the media. The concentrations of HMF and DHMF were monitored and HMF was added again after it was completely metabolized. A new cycle of reaction started within the second addition of substrate and similar reaction rates were observed. A yield of $96.80 \pm 4.05 \%$ was obtained within $60 \mathrm{~h}$ of biotransformation using a total concentration of $150 \mathrm{mM}$. Moreover, high selectivities (>98\%) were obtained through all the reaction (Figure 4a).

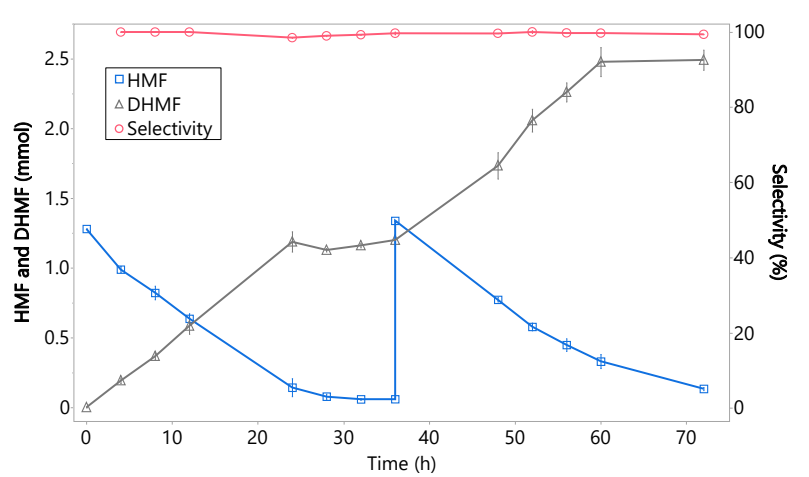

(a)

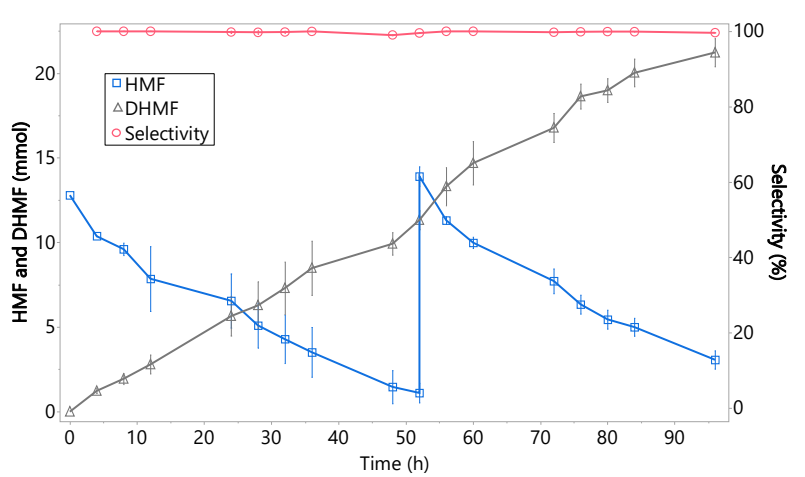

(b)

Figure 4. Substrate feeding approach. Conditions: $75 \mathrm{mM} \mathrm{HMF}, 1$ or $10 \mathrm{~mL}$ of an aqueous suspension of spores $\left(4.0 \times 10^{6}\right.$ spores $\left.\times \mathrm{mL}^{-1}\right) .160 \mathrm{rpm}, 28^{\circ} \mathrm{C}$. After HMF was almost consumed, $75 \mathrm{mM}$ were added; (a) $15 \mathrm{~mL}$ ME medium; (b) $150 \mathrm{~mL}$ ME medium. 


\subsection{Scale-up of the Reaction}

The scale-up is one of the major challenges in any biotechnological process due to the decrease in the process performance [32] and no data is reported for the biocatalytic production of DHMF with working volumes higher than $20 \mathrm{~mL}$ to the best of our knowledge.

Two scale-ups (5 and 10-fold) were performed in the shake flasks. The concentrations of DHMF produced were fitted to a linear regression with $R^{2}>0.95$ for the different samples (Figure 5), indicating a constant rate of DHMF production during the biotransformation regardless of the media volume.

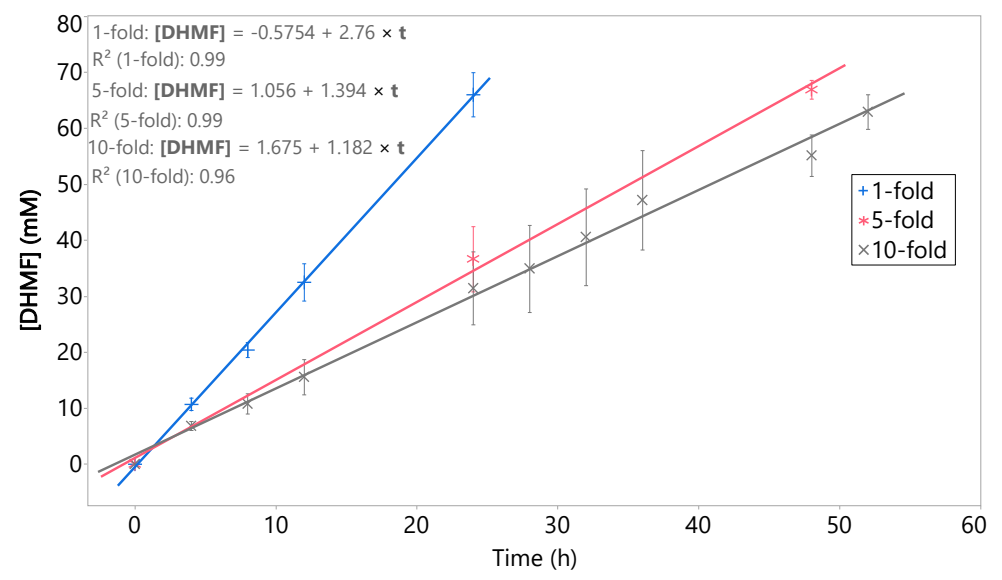

Figure 5. Effect of the scale-up of the reaction on reaction rates. Concentrations of HMF were fitted to a linear regression. Conditions: $75 \mathrm{mM} \mathrm{HMF}, 15,75$ or $150 \mathrm{~mL} \mathrm{ME}$ medium, 1, 5 or $10 \mathrm{~mL}$ of an aqueous suspension of spores $\left(4.0 \times 10^{6}\right.$ spores $\left.\times \mathrm{mL}^{-1}\right), \mathrm{pH} 7,160 \mathrm{rpm}, 28^{\circ} \mathrm{C}$.

The reaction rates were significantly slower when increasing the volume of media, which is expected in any scale-up process, as oxygen transfer and mixing may be negatively affected. However, final yields were well reproducible regardless of the working volume, and yields $>90 \%$ were obtained in all cases within 24,48 and $52 \mathrm{~h}$, respectively.

Once the practicality of the process was confirmed, the substrate feeding approach was scaled up (10-fold). HMF was added within $52 \mathrm{~h}$ of biotransformation and a second cycle of reaction started, confirming that the substrate-feeding is a feasible approach in this process even in a scale-up performed in shake flasks. The selectivity was high $(>98 \%)$ through all the reaction (Figure $4 b$ ).

\subsection{Bioreactor}

The growth of filamentous fungi in bioreactors presents difficulties due to the formation of mycelium, which causes different problems such as wrapping around the impellers, blockages and spread into nutrient and sampling feed lines, and an increase in broth viscosity [25]. However, due to the absence of formation of large filamentous mycelia by $F$. striatum under the conditions studied, none of the problems mentioned above was observed even with a low agitation rate of $160 \mathrm{rpm}$. The reaction rates were faster when compared with the previous scale-ups performed in shake flasks. Therefore, working in a bioreactor provided a much better environment for the biotransformation, which could be attributable to better oxygen transfer and mixing. Yields of $95 \%$ and a selectivity of a $98 \%$ were achieved within $40 \mathrm{~h}$ (Figure 6). The maximum productivity was $5.7 \mathrm{~g} \times \mathrm{dm}^{-3} \times \mathrm{d}^{-1}$. Although still modest, the process has potential for further development and improvement [14]. To the best of our knowledge, this is the first time that the productivities of the HMF reduction into DHMF are described at bench scale in a bioreactor. Therefore, we have demonstrated that the process can be scaled-up, and further optimization of the conditions in the bioreactor might improve the process performance. 


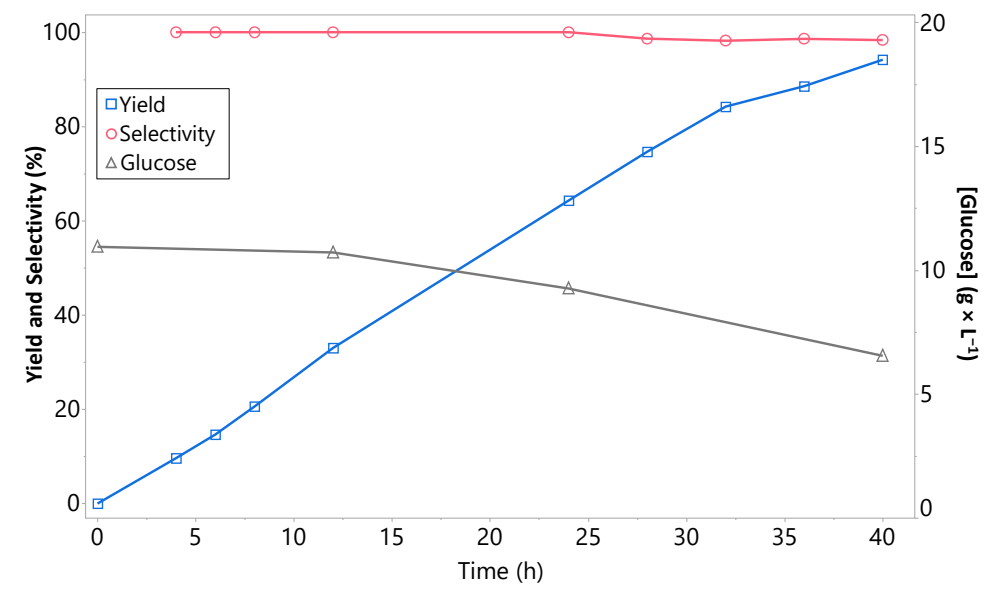

Figure 6. Biocatalytic production of DHMF at bioreactor scale. Conditions: $75 \mathrm{mM} \mathrm{HMF}, 1.3 \mathrm{~L} \mathrm{ME}$

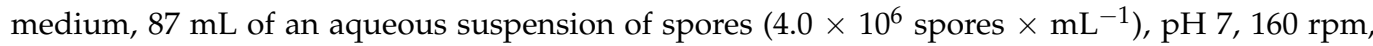
minimum aeration, $28^{\circ} \mathrm{C}$.

\subsection{Recovery of the DHMF from the Reaction Broth}

DHMF was recovered at gram scale from the reaction broth using ethyl acetate. The recovery yield was $85 \%$ and the yellow solid isolated had a purity over $90 \%$, measured by NMR.

\section{Materials and Methods}

\subsection{Materials}

The strain of F. striatum was isolated by our laboratory from food waste. The isolation was performed as follows: $10 \mathrm{~g}$ of food waste were added to $90 \mathrm{~mL}$ of saline peptone water and homogenized for 2 min with a paddle blender. Then $100 \mu \mathrm{L}$ were plated in Petri dishes containing potato dextrose agar. After five days of growth at $28{ }^{\circ} \mathrm{C}$, the fungi grown in the Petri dishes were isolated by plating them separately in new plates with the same medium. F. culmorum was obtained from the Spanish Type Culture Collection (CECT2148). F. sporotrichioides (B3), F. tricinctum (T263), F. poae (G1), F. chlamydosporium (T773) and F. sambucinum (B6) belong to the culture collection of the Food Technology department (University of Lleida). HMF (98\%) was purchased from Fluorochem Ltd. (Hadfield, UK). DHMF (97\%) was purchased from Apollo Scientific (Stockport, UK). 5Acetoxymethyl-2-furaldehyde and 5-methylfurfural were purchased from Sigma-Aldrich (Misuri, USA). Ethyl acetate was purchased from Honeywell (Morristown, USA).

\subsection{Cultivation of Fusarium Cells}

Fusarium strains were maintained by replications on malt extract agar (MEA: $20 \mathrm{~g} \times \mathrm{L}^{-1}$ glucose, $20 \mathrm{~g} \times \mathrm{L}^{-1}$ malt extract, $1 \mathrm{~g} \times \mathrm{L}^{-1}$ peptones from soybean, $15 \mathrm{~g} \times \mathrm{L}^{-1}$ agar) at $4{ }^{\circ} \mathrm{C}$. Before biotransformation experiments, they were activated in MEA for seven days at $28^{\circ} \mathrm{C}$.

\subsection{Screening}

The activated strains of the Fusarium species were inoculated into flasks containing $15 \mathrm{~mL}$ of malt extract media (ME: $20 \mathrm{~g} \times \mathrm{L}^{-1}$ glucose, $20 \mathrm{~g} \times \mathrm{L}^{-1}$ malt extract, $1 \mathrm{~g} \times \mathrm{L}^{-1}$ peptones from soybean) by the addition of three discs of $8 \mathrm{~mm}$ from the Petri dishes containing MEA. $\mathrm{pH}$ was previously adjusted at 7 with $1 \mathrm{M} \mathrm{NaOH}$. The flasks were incubated in a rotatory shaker at $28^{\circ} \mathrm{C}$ and $160 \mathrm{rpm}$. After three days, HMF was added to the media in order to obtain the desired concentration of the substrate (50 $\mathrm{mM})$.

\subsection{Biotransformation Experiments}

In a standard experiment, the activated strain of $F$. striatum was inoculated into flasks containing $15 \mathrm{~mL}$ of ME either by the addition of fungal discs of $8 \mathrm{~mm}$ or by the addition 
of $1 \mathrm{~mL}$ of an aqueous suspension of spores $\left(4.0 \times 10^{6}\right.$ spores $\left.\times \mathrm{mL}^{-1}\right)$. $\mathrm{pH}$ was previously adjusted at 7 with $1 \mathrm{M} \mathrm{NaOH}$. The flasks were incubated in a rotatory shaker at $28^{\circ} \mathrm{C}$ and $160 \mathrm{rpm}$. After three days HMF was added to the media in order to obtain the desired concentration of the substrate $(50-100 \mathrm{mM})$.

\subsection{Effect of Inoculum Size, Glucose Concentration and $p H$}

A $2^{3}$ factorial design was used to assess the effects of the inoculum size, the $\mathrm{pH}$ and the initial concentration of glucose in the media over the DHMF production. Each factor was run at two levels and the design was replicated twice. The response variable was the mmol of DHMF produced and it was analyzed within 24 and $72 \mathrm{~h}$ after the first HMF addition. HMF was added sequentially three times in time intervals of $24 \mathrm{~h}$.

\subsection{Sporulation of F. Striatum}

F. striatum was incubated in three different malt extract media (ME: $20 \mathrm{~g} \times \mathrm{L}^{-1}$ glucose, $20 \mathrm{~g} \times \mathrm{L}^{-1}$ malt extract, $1 \mathrm{~g} \times \mathrm{L}^{-1}$ peptones from soybean, $15 \mathrm{~g} \times \mathrm{L}^{-1}$ agar; ME-: $20 \mathrm{~g} \times \mathrm{L}^{-1}$ glucose, $20 \mathrm{~g} \times \mathrm{L}^{-1}$ malt extract, $15 \mathrm{~g} \times \mathrm{L}^{-1}$ agar; and ME- -: $20 \mathrm{~g} \times \mathrm{L}^{-1}$ glucose, $10 \mathrm{~g} \times \mathrm{L}^{-1}$ malt extract, $15 \mathrm{~g} \times \mathrm{L}^{-1}$ agar) in either presence or absence of visible light for 10 days. Spores were counted with a Neubauer chamber.

\subsection{Scale-up in the Shake Flasks}

The activated strain of $F$. striatum was inoculated into flasks containing 75 or $150 \mathrm{~mL}$ of ME by the addition of 5 or $10 \mathrm{~mL}$ of an aqueous suspension of spores $\left(4.0 \times 10^{6}\right.$ spores $\left./ \mathrm{mL}\right)$, respectively. $\mathrm{pH}$ was previously adjusted at 7 with $1 \mathrm{M} \mathrm{NaOH}$. The flasks were incubated in a rotatory shaker at $28{ }^{\circ} \mathrm{C}$ and $160 \mathrm{rpm}$. After three days, HMF was added to the media in order to obtain the desired concentration of substrate $(75 \mathrm{mM})$.

\subsection{Scale-up in the Bioreactor}

The activated strain of F. striatum was inoculated into the bioreactor containing $1.3 \mathrm{~L}$ of ME by the addition of $87 \mathrm{~mL}$ of an aqueous suspension of spores $\left(4.0 \times 10^{6}\right.$ spores $\left./ \mathrm{mL}\right)$. The working conditions were $28^{\circ} \mathrm{C}, 160 \mathrm{rpm}, \mathrm{pH} 7$, minimum aeration. After three days of growth, HMF was added to the media in order to obtain the desired concentration of substrate $(75 \mathrm{mM})$.

\subsection{Recovery of DHMF from the Reaction Media}

The biotransformation broth resulting from the 5-fold scale-up assay was extracted three times with an equal volume of ethyl acetate. The organic extracts were joined and dried over $\mathrm{Na}_{2} \mathrm{SO}_{4}$ anh. The mixture was filtrated, and the solvent was evaporated to dryness yielding a yellow solid. Finally, the crude reaction product was analyzed by NMR to assess its purity.

\subsection{GC-FID Analysis}

The compounds were extracted from the aqueous aliquots using ethyl acetate. GC-FID analyses were performed with an Agilent 7890 GC (Agilent Technologies, Palo Alto, CA, USA) with an ultra-inert splitless liner containing a piece of glass wool coupled to an FID detector. For the chromatographic separation, an FFAP $(30 \mathrm{~m} \times 0.25 \mathrm{~mm}$ i.d.; $0.25 \mu \mathrm{m}$ film thickness) column from Agilent was used at a constant flow of $1 \mathrm{~mL} / \mathrm{min}$ using hydrogen as carrier gas. Injector temperature was $230^{\circ} \mathrm{C}$, and the oven program was $100{ }^{\circ} \mathrm{C}$ (held for $1 \mathrm{~min}$ ) to $240^{\circ} \mathrm{C}$ at $20^{\circ} \mathrm{C} / \mathrm{min}$ (held for $5 \mathrm{~min}$ ). Calibration curves were performed periodically for the quantification of the compounds using 5-acetoxymethyl-2-furaldehyde as internal standard.

\subsection{Statistical Analysis}

The statistical analyses were performed using the software JMP Pro 14 (SAS). The results obtained were subjected to analysis of variance (ANOVA). Statistical significance 
was assessed with the $p$-value in Fisher's test with a 95\% confidence level. Tukey HSD test was performed to discriminate among the means. All experiments were conducted at least in duplicate, and the values are expressed as the means \pm standard deviations. The assumption of normality was tested using Shapiro-Wilks normality test.

\section{Conclusions}

In the present study, we report the biocatalytic upgrade of HMF by different Fusarium species at concentrations of substrate $\geq 50 \mathrm{mM}$ for the first time to the best of our knowledge. A new F. striatum strain isolated from food waste has shown to be a good biocatalyst for the biotransformation of HMF to DHMF, transforming $75 \mathrm{mM}$ of HMF with quantitative yields and a high selectivity within $24 \mathrm{~h}$. A substrate-feeding approach allowed a higher final concentration of product in the media, which is highly desirable in any biocatalytic process and one of the harder challenges in the biocatalytic upgrade of toxic substrates. Finally, the growth of F. striatum in the media, under the conditions studied, allowed a scale-up of the process at bioreactor scale $(1.3 \mathrm{~L})$ with a high yield $(95 \%)$ and selectivity $(98 \%)$. The successful recovery of DHMF with a high purity from the reaction broth by organic solvent extraction closed an efficient process.

Furthermore, results obtained indicate that F. striatum may be a perfect candidate to perform the biotransformation of HMF using lignocellulosic hydrolysates as biotransformation media, benefiting from both HMF and sugars present. Its application would add value to the residues by metabolizing the HMF present, toxic for the sugar fermenting strains, and simultaneously producing high concentrations of DHMF. This approach is currently being studied.

Supplementary Materials: The following are available online at https:/ / www.mdpi.com/2073-434 4/11/2/216/s1, Figure S1: F. striatum growth in malt extract broth, Figure S2: Chromatograms from the GC-FID measurements, Figure S3: F. striatum growth in the bioreactor, Figure S4: ${ }^{1} \mathrm{H}$ NMR in $\mathrm{DMSO}_{\mathrm{d} 6}$ of the DHMF recovered as a yellow solid.

Author Contributions: Conceptualization, A.M. and R.C.-G.; methodology, A.M and N.S.; software, A.M.; validation, A.M., R.C.-G. and M.T.; formal analysis, A.M.; investigation, A.M.; resources, R.C.-G.; data curation, R.C.-G.; writing-original draft preparation, A.M.; writing-review and editing, A.M. and R.C.-G.; visualization, N.S and M.T.; supervision, R.C.-G.; project administration, R.C.-G.; funding acquisition, R.C.-G. All authors have read and agreed to the published version of the manuscript.

Funding: This work was partially supported by the Spanish government (PID2019-110735RB-C21, MICIN/FEDER) and the Catalan Government (FI_B1_00135).

Data Availability Statement: Data available on request.

Acknowledgments: The authors would like to thank the Catalan Government for the quality accreditation given to their research group 2017 SGR 828. A.M would like to thank "Generalitat de Catalunya" for Grant FI Agaur.

Conflicts of Interest: The authors declare no conflict of interest.

\section{References}

1. Liguori, R.; Amore, A.; Faraco, V. Waste valorization by biotechnological conversion into added value products. Appl. Microbiol. Biotechnol. 2013, 97, 6129-6147. [CrossRef]

2. Ali, S.S.; Nugent, B.; Mullins, E.; Doohan, F.M. Fungal-mediated consolidated bioprocessing: The potential of Fusarium oxysporum for the lignocellulosic ethanol industry. AMB Express 2016, 6, 1-13. [CrossRef]

3. Zhang, Y.; Zhang, J.; Su, D. 5-Hydroxymethylfurfural: A key intermediate for efficient biomass conversion. J. Energy Chem. 2015, 24, 548-551. [CrossRef]

4. Hu, L.; He, A.; Liu, X.; Xia, J.; Xu, J.; Zhou, S.; Xu, J. Biocatalytic Transformation of 5-Hydroxymethylfurfural into High-Value Derivatives: Recent Advances and Future Aspects. ACS Sustain. Chem. Eng. 2018, 6, 15915-15935. [CrossRef]

5. Almeida, J.R.M.; Bertilsson, M.; Gorwa-Grauslund, M.-F.; Gorsich, S.; Lidén, G. Metabolic effects of furaldehydes and impacts on biotechnological processes. Appl. Microbiol. Biotechnol. 2009, 82, 625-638. [CrossRef] 
6. Klinke, H.B.; Thomsen, A.B.; Ahring, B.K. Inhibition of ethanol-producing yeast and bacteria by degradation products produced during pre-treatment of biomass. Appl. Microbiol. Biotechnol. 2004, 66, 10-26. [CrossRef]

7. Zabed, H.; Sahu, J.N.; Suely, A.; Boyce, A.N.; Faruq, G. Bioethanol production from renewable sources: Current perspectives and technological progress. Renew. Sustain. Energy Rev. 2017, 71, 475-501. [CrossRef]

8. Ran, H.; Zhang, J.; Gao, Q.; Lin, Z.; Bao, J. Analysis of biodegradation performance of furfural and 5-hydroxymethylfurfural by Amorphotheca resinae ZN1. Biotechnol. Biofuels 2014, 7, 51. [CrossRef]

9. Feldman, D.; Kowbel, D.J.; Glass, N.L.; Yarden, O.; Hadar, Y. Detoxification of 5-hydroxymethylfurfural by the Pleurotus ostreatus lignolytic enzymes aryl alcohol oxidase and dehydrogenase. Biotechnol. Biofuels 2015, 8, 1-11. [CrossRef] [PubMed]

10. Wang, X.; Gao, Q.; Bao, J. Transcriptional analysis of Amorphotheca resinae ZN1 on biological degradation of furfural and 5-hydroxymethylfurfural derived from lignocellulose pretreatment. Biotechnol. Biofuels 2015, 8, 1-13. [CrossRef] [PubMed]

11. Hu, L.; Lin, L.; Wu, Z.; Zhou, S.; Liu, S. Recent advances in catalytic transformation of biomass-derived 5-hydroxymethylfurfural into the innovative fuels and chemicals. Renew. Sustain. Energy Rev. 2017, 74, 230-257. [CrossRef]

12. Zhang, J.; Wang, T.; Tang, X.; Peng, L.; Wei, J.; Lin, L. Methods in the Synthesis and Conversion of 2,5-Bis-(hydroxymethyl)furan from Bio-derived 5-Hydroxymethylfurfural and its Great Potential in Polymerization. BioResources 2018, 13, 7137-7154. [CrossRef]

13. Maniar, D.; Jiang, Y.; Woortman, A.J.J.; Van Dijken, J.; Loos, K. Furan-Based Copolyesters from Renewable Resources: Enzymatic Synthesis and Properties. ChemSusChem 2019, 12, 990-999. [CrossRef]

14. De María, P.D.; Guajardo, N. Biocatalytic Valorization of Furans: Opportunities for Inherently Unstable Substrates. ChemSusChem 2017, 10, 4123-4134. [CrossRef] [PubMed]

15. He, Y.-C.; Jiang, C.-X.; Chong, G.-G.; Di, J.-H.; Ma, C.-L. Biological synthesis of 2,5-bis(hydroxymethyl)furan from biomass-derived 5-hydroxymethylfurfural by E. coli CCZU-K14 whole cells. Bioresour. Technol. 2018, 247, 1215-1220. [CrossRef]

16. Li, Y.-M.; Zhang, X.-Y.; Li, N.; Xu, P.; Lou, W.-Y.; Zong, M.-H. Biocatalytic Reduction of HMF to 2,5-Bis(hydroxymethyl)furan by HMF-Tolerant Whole Cells. ChemSusChem 2017, 10, 372-378. [CrossRef]

17. Xu, Z.-H.; Cheng, A.-D.; Xing, X.-P.; Zong, M.-H.; Bai, Y.-P.; Li, N. Improved synthesis of 2,5-bis(hydroxymethyl)furan from 5-hydroxymethylfurfural using acclimatized whole cells entrapped in calcium alginate. Bioresour. Technol. 2018, 262, 177-183. [CrossRef] [PubMed]

18. Xia, Z.-H.; Zong, M.-H.; Li, N. Catalytic synthesis of 2,5-bis(hydroxymethyl)furan from 5-hydroxymethylfurfual by recombinant Saccharomyces cerevisiae. Enzym. Microb. Technol. 2020, 134, 109491. [CrossRef]

19. Liu, Z.L.; Slininger, P.J.; Gorsich, S.W. Enhanced Biotransformation of Furfural and Hydroxymethylfurfural by Newly Developed Ethanologenic Yeast Strains. Appl. Biochem. Biotechnol. 2005, 121, 451-460. [CrossRef]

20. Ra, C.H.; Jeong, G.-T.; Shin, M.K.; Kim, S.-K. Biotransformation of 5-hydroxymethylfurfural (HMF) by Scheffersomyces stipitis during ethanol fermentation of hydrolysate of the seaweed Gelidium amansii. Bioresour. Technol. 2013, 140, 421-425. [CrossRef] [PubMed]

21. Zheng, Y.-K.; Qiao, X.-G.; Miao, C.-P.; Liu, K.; Chen, Y.-W.; Xu, L.-H.; Zhao, L.-X. Diversity, distribution and biotechnological potential of endophytic fungi. Ann. Microbiol. 2015, 66, 529-542. [CrossRef]

22. Wösten, H.A.B. Filamentous fungi for the production of enzymes, chemicals and materials. Curr. Opin. Biotechnol. 2019, 59, 65-70. [CrossRef] [PubMed]

23. Pessôa, M.G.; Paulino, B.N.; Mano, M.C.R.; Neri-Numa, I.A.; Molina, G.; Pastore, G.M. Fusarium species—a promising tool box for industrial biotechnology. Appl. Microbiol. Biotechnol. 2017, 101, 3493-3511. [CrossRef] [PubMed]

24. Zeng, Y.-J.; Yang, H.-R.; Wu, X.-L.; Peng, F.; Huang, Z.; Pu, L.; Zong, M.-H.; Yang, J.-G.; Lou, W.-Y. Structure and immunomodulatory activity of polysaccharides from Fusarium solani DO7 by solid-state fermentation. Int. J. Biol. Macromol. 2019, 137, 568-575. [CrossRef]

25. Moreira, M.T.; Feijoo, G.; Lema, J.M. Fungal Bioreactors: Applications to White-Rot Fungi. Rev. Environ. Sci. Bio Technol. 2003, 2, 247-259. [CrossRef]

26. Singh, V.; Haque, S.; Niwas, R.; Srivastava, A.; Pasupuleti, M.; Tripathi, C.K.M. Strategies for Fermentation Medium Optimization: An In-Depth Review. Front. Microbiol. 2017, 7, 2087. [CrossRef]

27. Papagianni, M. Fungal morphology and metabolite production in submerged mycelial processes. Biotechnol. Adv. 2004, 22, 189-259. [CrossRef]

28. Liaud, N.; Giniés, C.; Navarro, D.; Fabre, N.; Crapart, S.; Herpoël-Gimbert, I.; Levasseur, A.; Raouche, S.; Sigoillot, J.-C. Exploring fungal biodiversity: organic acid production by 66 strains of filamentous fungi. Fungal Biol. Biotechnol. 2014, 1, 1-10. [CrossRef]

29. Su, Y.Y.; Qi, Y.L.; Cai, L. Induction of sporulation in plant pathogenic fungi. Mycology 2012, 3, 195-200. [CrossRef]

30. Stiborova, H.; Branska, B.; Vesela, T.; Lovecka, P.; Stranska, M.; Hajslova, J.; Jiru, M.; Patakova, P.; Demnerova, K. Transformation of raw feather waste into digestible peptides and amino acids. J. Chem. Technol. Biotechnol. 2016, 91, 1629-1637. [CrossRef]

31. Sheldon, R.A.; Woodley, J.M. Role of Biocatalysis in Sustainable Chemistry. Chem. Rev. 2018, 118, 801-838. [CrossRef] [PubMed]

32. Tufvesson, P.; Fu, W.; Jensen, J.S.; Woodley, J.M. Process considerations for the scale-up and implementation of biocatalysis. Food Bioprod. Process. 2010, 88, 3-11. [CrossRef] 